\title{
Associação entre características da parte aérea e do sistema radicular em mudas de guaranazeiro por correlações canônicas
}

\author{
Firmino José do NASCIMENTO FILHO ${ }^{1}$, André Luiz ATROCH², Paulo Roberto CECON³
}

\begin{abstract}
RESUMO
Este trabalho teve como objetivo quantificar o grau de asociação entre variáveis de parte aérea e de raízes em mudas clonadas de guaranazeiro, utilizando-se correlaçóes canônicas, a fim de aperfeiçoar o procedimento de seleção de mudas para garantir o aumento da porcentagem de sobrevivência das mudas após o plantio. Foram avaliados dois grupos de variáveis em mudas aptas ao plantio definitivo de 36 clones de guaranazeiro. O delineamento usado foi o aleatorizado em blocos com cinco repetiçóes e 10 plantas por parcela, sob condiçóes de viveiro. Os caracteres avaliados foram submetidos à análise de correlaçóes canônicas. Utilizou-se a análise de correlaçóes canônicas. O grupo de variáveis da parte aérea não se mostrou independente do grupo de variáveis do sistema radicular. Através de seleção baseada em variáveis da parte aérea pode-se melhorar o sistema radicular, principalmente através do maior comprimento do ramo (CRA). A seleção de clones de guaraná para maior peso de raiz pode ser efetuada de forma indireta, realizando-se mensurações do comprimento dos ramos, o que evita a necessidade de se destruir as mudas.
\end{abstract}

PALAVRAS-CHAVE: Paullinia cupana, seleção indireta, sobrevivência de mudas.

\section{Canonical correlations among characteristics of shoots and roots system in guarana seedlings}

\section{ABSTRACT}

This study aimed to quantify the degree of association between variables of shoots and roots system of seedlings cloned from guarana, using canonical correlations, in order to improve the procedure of selection of seedlings to ensure increased survival percentage of seedlings after planting. Two groups of variables suitable for final planting seedlings in 36 guarana clones. The experimental design was a randomized complete block with five replications and 10 plants per plot, under nursery conditions. We used the canonical correlation analysis. The group of variables of shoot is not independent of variable group of root system. Through selection based on variables from the air, you can improve the root system, mainly through the greater length of the branch (CRA). Can practice the selection of clones of guarana for increased root weight without the need to destroy the seedlings carrying only measurements of the length of the branches.

KEY-WORDS: Paullinia cupana, indirect selection, seedlings survival.

\footnotetext{
${ }^{1}$ Eng. Agr., Doutor em Genética e Melhoramento de Plantas, Pesquisador da Embrapa Amazônia Ocidental, Manaus, AM. firmino.filho@cpaa.embrapa.br

2 Eng. Agr., Mestre em Genética e Melhoramento de Plantas, Doutor em Genética, Conservação e Biologia Evolutiva, Pesquisador da Embrapa Amazônia Ocidental, Manaus, AM. andre.atroch@cpaa.embrapa.br - Autor para correspondência

${ }^{3}$ Eng. Agr., Doutor em Estatística, Professor do Departamento de Informática e Estatísticada Universidade Federal de Viçosa, Viçosa, MG. cecon@ufv.br
} 


\section{INTRODUÇÃO}

A importância dos estudos de caracteres correlacionados tem sido evidenciada nos programas de melhoramento e, segundo Ramalho et al. (1993), a correlação entre caracteres e o componente genético das correlações são de grande importância para a seleção e o progresso genético.

A propagação vegetativa ou assexuada é de grande interesse para o melhorista, pois permite a fixação de genótipos, em qualquer fase do programa de melhoramento. Porém, para a cultura do guaraná (Paullinia cupana var. sorbilis (Mart.) Ducke), após o domínio da técnica de enraizamento de estacas, constatou-se que os níveis de sobrevivência das mudas, após o plantio definitivo, eram irregulares e não satisfatórios para diversos genótipos (Escobar 1986).

O êxito no estabelecimento de culturas perenes depende de uma alta taxa de sobrevivência de mudas no campo. Segundo Escobar (1986), na formação das lavouras de guaraná, deve-se selecionar clones que proporcionem alta sobrevivência (acima de $90 \%$ ), com o objetivo de garantir ao produtor um maior número de plantas por hectare, em decorrência apenas do uso de genótipos que mantenham em seus propágulos informaçóes morfogenéticas capazes de garantir a formação de mudas que se enquadrem no padrão de seleção para o plantio definitivo. Desde a década de 1980 os critérios de seleção de mudas de guaranazeiro são baseados apenas em características da parte aérea, como vigor das mudas e número de folhas aos oito meses de idade, sem nenhuma avaliação referente ao sistema radicular.

A análise de correlaçóes canônicas é uma maneira simples de reduzir as complexidades envolvidas em relacionar dois conjuntos de variáveis. Apesar disso, o método apresenta algumas dificuldades nas interpretaçôes das correlaçôes. Algumas vezes, a análise pode identificar várias correlaçôes que, embora significativas, associam diferentes combinaçóes de variáveis utilizadas nos grupos I e II e, consequentemente, dificultam a interpretação. Isto é possível porque os pares canônicos são representados por funçôes lineares que podem não refletir partes significativas das variâncias das respectivas variáveis. A técnica de encontrar essas combinaçóes lineares e suas respectivas correlaçóes foi proposta por Hotelling (1933; 1936).

De uma maneira geral, considera-se que o primeiro grupo é estabelecido por $p$ variáveis e o segundo por $q$ variáveis. O número de correlaçóes canônicas é igual ao número de variáveis do menor grupo. Nesta análise, o objetivo é estimar a máxima correlação entre as combinaçóes lineares das variáveis do grupo I e do grupo II, bem como estimar os respectivos coeficientes de ponderação das variáveis em cada combinação linear (Cruz e Regazzi 2004).

Com um grande número de variáveis, a análise de correlaçóes canônicas possibilita encontrar algumas poucas combinaçôes lineares de variáveis em cada grupo, a fim de estudar as inter-relaçôes entre as mesmas e, assim, simplificar a análise em um sistema de coordenadas que permitam estimar as inter-relaçóes (Timm 1975 citado por Correia 1993). O princípio básico em uma correlação canônica é desenvolver uma combinação linear em cada um dos conjuntos de variáveis, tal que a correlação entre os dois conjuntos seja maximizada. $\mathrm{Na}$ correlação canônica não existe a distinção entre variável independente e dependente, existem somente dois conjuntos de variáveis em que se busca a máxima correlação entre ambos.

A técnica da análise de correlações canônicas é muito usada em estudos exploratórios. Um pesquisador pode ter um grande conjunto de variáveis, mas pode estar interessado em estudar somente algumas poucas combinaçóes lineares de variáveis desse conjunto. Poderá então, estudar aquelas combinações lineares, cujas correlaçóes são mais elevadas. Uma característica importante da análise de correlaçôes canônicas é que, diferentemente dos componentes principais, ela é invariante à escala das variáveis (Timm 1975 citado por Correia 1993).

Em cafeeiro utilizou-se a técnica de correlaçôes canônicas entre grupos de variáveis ambientais, lâminas de irrigação via gotejamento e predação por vespas na densidade populacional de Leucoptera coffeella (bicho-mineiro-do-cafeeiro). Concluiuse que a maior precipitação pluvial, radiação solar e lâminas de irrigação reduzem a densidade populacional do bicho-mineiro. Além disso, o aumento na densidade das vespas predadoras foi dependente dos níveis populacionais de L. coffeella (Fernandes et al. 2009).

Uma estratégia utilizada pelos melhoristas de batata é a eliminação de um grande número de clones nas primeiras geraçóes de seleção, para reduzir os custos e o trabalho de manutenção e multiplicação destes clones. Rigão et al. (2009) utilizaram a técnica de correlaçôes canônicas visando relacionar caracteres de tubérculos plantados com os colhidos, para auxiliar a seleção precoce. Observou-se que há relação das diferentes características dos tubérculos plantados e daqueles colhidos. $\mathrm{O}$ comprimento apresentou a maior associação entre os tubérculos plantados e colhidos. Tubérculos compridos resultam na produção de tubérculos alongados.

Este trabalho teve como objetivo quantificar o grau de associação entre variáveis de parte aérea e de raízes em mudas clonadas de guaranazeiro, utilizando-se correlaçóes canônicas, a fim de aperfeiçoar o procedimento de seleção de mudas para garantir o aumento da porcentagem de sobrevivência das mudas após o plantio.

\section{MATERIAL E MÉTODOS}

O trabalho foi realizado no Campo Experimental da Embrapa Amazônia Ocidental, em Manaus, AM, localizado a 
uma latitude de $03^{\circ} 08^{\prime} 05^{\prime}$ ' $S$, longitude de 60 $01^{\prime} \mathrm{W}$ de GRT e altitude de $50 \mathrm{~m}$ acima do nível do mar; tipo climático Afi da classificação de Köppen (clima tropical chuvoso), caracterizado por ter temperatura média do mês mais frio nunca inferior a $18^{\circ} \mathrm{C}$, e precipitaçáo pluvial do mês mais seco, acima de 60 mm (Embrapa 1998).

Foram avaliados, em mudas aptas ao plantio definitivo de 36 clones de guaranazeiro, dois grupos de variáveis: grupo I, constituído por sete variáveis do sistema radicular, quais sejam, número de raiz (NRZ); comprimento médio de raiz (CPMRZ); diâmetro médio de raiz (DMRZ); peso de raiz seca ao ar (PRZSA); volume de raiz (VRZ); índice de área de raiz (IARZ); peso da matéria seca da raiz (PSRZ); e grupo II, reunindo 19 variáveis da parte aérea: peso da matéria fresca da estaca remanescente (PFEr); peso da matéria seca da estaca remanescente (PSEr); peso da matéria fresca do ramo (PFRA); peso da matéria seca do ramo (PSRA); comprimento do ramo (CRA); número de gemas (NG); diâmetro basal do ramo (D1); diâmetro mediano do ramo (D2); diâmetro apical do ramo (D3); diâmetro médio do ramo (DMRA); peso da matéria fresca do pecíolo (PFPC); peso da matéria seca do pecíolo (PSPC); número de folhas (NFH); número de folíolos (NFL); peso da matéria fresca dos folíolos (PFFL); peso da matéria seca dos folíolos (PSFL); área foliar (AFLH); peso da matéria seca das folhas (PSFH) e peso da matéria seca da parte aérea (PSPA).

O delineamento usado foi o aleatorizado em blocos com cinco repetiçôes e 10 plantas por parcela, sob condiçôes de viveiro. Porém, na fase destrutiva das mudas, quando houve o registro das variáveis da parte aérea e do sistema radicular, foram selecionadas ao acaso três plantas em cada parcela.

Utilizou-se a análise de correlaçôes canônicas que, segundo Cruz e Regazzi (2004), caracteriza-se por avaliar as relaçôes entre dois grupos influenciados, no mínimo, por duas variáveis.

A significância da hipótese de que todas as possíveis correlaçôes canônicas são nulas pode ser avaliado pelo teste aproximado de $x^{2}$, que, segundo Dunteman (1984) citado por Cruz e Regazzi (2004), é dado por:

$$
\begin{aligned}
& \chi^{2}=-\operatorname{tog}\left[\prod_{\mathrm{i}=1}^{\mathrm{s}}\left(1-\mathrm{r}_{\mathrm{i}}^{2}\right)\right], \text { em que: } \\
& \mathrm{t}=\mathrm{n}-0,5(\mathrm{p}+\mathrm{q}+3) ; \\
& \mathrm{n}: \text { número de observaçóes experimentais. }
\end{aligned}
$$

A estatística está associada a pq graus de liberdade. Se a hipótese é rejeitada, testa-se a hipótese $\mathrm{H}_{0}=\rho_{\mathrm{k}}>0$ e $\rho_{\mathrm{k}+1}=\rho_{\mathrm{k}+2}=\ldots=\rho_{\mathrm{s}}=0$, por meio de:

$$
-\operatorname{tog}_{\mathrm{e}}\left[\prod_{i=k+1}^{\mathrm{s}}\left(1-\mathrm{r}_{\mathrm{i}}^{2}\right)\right] \text {, que está associada a } \chi^{2} \operatorname{com}(\mathrm{p}-\mathrm{k})
$$

(q-k) graus de liberdade.

As análises foram realizadas utilizando-se o programa Genes (Cruz 2001).

\section{RESULTADOS E DISCUSSÃO}

Observando-se as correlaçóes canônicas e seus pares canônicos (Tabela 1) constatou-se que os grupos de variáveis não são independentes, de modo que as variáveis relacionadas ao sistema radicular definidas no grupo I mostraram fortes correlaçôes com as variáveis relacionadas à parte aérea do grupo II.

Apenas o primeiro par canônico foi significativo pelo teste de $x^{2}(r=0,952, p<0,01)$. Deste modo pode-se, por meio da seleção baseada nas variáveis da parte aérea, melhorar o sistema radicular, principalmente por meio do maior comprimento do ramo (CRA) por estar associado ao maior peso da matéria seca de raiz (PSRZ). Assim, pode-se praticar seleçáo de clones de guaraná, para maior peso de raiz, sem a necessidade de destruir as mudas, de modo indireto, realizando-se apenas mensuraçóes do comprimento dos ramos.

Tabela 1 - Coeficientes de ponderação, correlações canônicas (r) e quatro pares canônicos estimados entre variáveis do sistema radicular (grupo I), da parte aérea (grupo II) em mudas clonais de guaranazeiro.

\begin{tabular}{cccccc}
\hline \multirow{2}{*}{ Grupos } & Caracteres & \multicolumn{4}{c}{ Pares canônicos } \\
\cline { 3 - 6 } & & $1^{\circ}$ & $2^{\circ}$ & $3^{\circ}$ & $4^{\circ}$ \\
\hline \multirow{4}{*}{ I } & NRZ & 0,17 & 1,18 & $-0,57$ & 0,26 \\
& CPMRZ & 0,22 & 1,73 & 0,61 & $-0,99$ \\
& DMRZ & 0,26 & 0,00 & 0,24 & 1,47 \\
& PSRZ & 0,61 & $-1,74$ & $-0,58$ & $-0,36$ \\
\hline \multirow{4}{*}{$\|$} & PFEr & 0,11 & 0,08 & $-0,39$ & $-0,08$ \\
& PSRA & $-0,17$ & $-1,16$ & $-0,20$ & $-0,31$ \\
& CRA & 0,58 & 0,59 & 0,73 & 0,07 \\
& NG & 0,09 & 0,21 & $-0,21$ & 0,16 \\
& D1 & 0,25 & 0,51 & 0,04 & $-0,15$ \\
& D3 & $-0,07$ & $-0,31$ & 0,03 & $-0,37$ \\
& DMRA & 0,09 & 0,00 & $-0,12$ & 0,47 \\
& PSPC & 0,18 & 0,42 & $-0,19$ & $-0,02$ \\
\hline & NFL & 0,09 & $-0,65$ & 0,13 & 0,10 \\
\hline & r & 0,95 & 0,61 & 0,55 & 0,38 \\
\hline & Probabilidade* & 0,00 & 0,28 & 0,41 & 0,62 \\
\hline
\end{tabular}

*Teste Qui-quadrado

NRZ: número de raiz; CPMRZ: comprimento médio de raiz; DMRZ: diâmetro médio de raiz; PSRZ: peso da matéria seca da raiz; PFEr: peso da matéria fresca da estaca remanescente; PSRA: peso da matéria seca do ramo; CRA: comprimento do ramo; NG: número de gemas; D1: diâmetro basal do ramo; D3: diâmetro apical do ramo; DMRA: diâmetro médio do ramo; PSPC: peso da matéria seca do pecíolo; NFL: número de folíolos. 
Como os outros três pares canônicos foram não significativos $(p>0,05)$, pode-se considerar que as variáveis menos importantes para as correlaçóes entre os grupos foram a CPMRZ (grupo I) e DMRA (grupo II), CPMRZ (grupo I) e CRA (grupo II) e PSRZ e CPMRZ (grupo I) e PSRA (grupo II), devido aos maiores coeficientes de ponderaçóes associados aos $2^{\circ}, 3^{\circ}$ e $4^{\circ}$ pares canônicos, respectivamente. Deste modo, as seleçóes praticadas em DMRA e CRA (variáveis da parte aérea), irão provocar poucas alteraçóes na variável CPMRZ (variável do sistema radicular). Portanto, esta variável CPMRZ necessita ser monitorada. Apesar das variáveis PSRZ e PSRA serem pouco importantes para a correlaçâo entre os dois grupos, esta interpretação não seria importante para a discussão das variáveis, dado que a variável CRA está altamente correlacionada com a variável PSRZ.

Diversos autores tem realizado trabalhos de associação de caracteres em diferentes espécies (Carvalho et al. 1999; Coimbra et al. 2000; Kurek et al. 2001), entretanto com guaraná os trabalhos são escassos. Em guaranazeiro, Nascimento Filho et al. (1993) utilizaram a análise de caminhamento entre caracteres da parte aérea e do sistema radicular com o objetivo de determinar as interrelaçóes entre alguns caracteres, concluindo que o diâmetro basal do ramo é um indicador indireto da condição do sistema radicular.

Assim, com base nos resultados apresentados pela técnica das correlaçóes canônicas, pode-se concluir que para uma boa formaçáo e sobrevivência de mudas clonais no campo, as variáveis CRA (parte aérea) e CPMRZ (sistema radicular) devem ser incorporadas num processo de seleção. No entanto, apesar da variável CPMRZ ser a menos importante do grupo I para a correlaçấo canônica com as variáveis do grupo II, a mesma apresenta alta correlaçáo simples $(r=0,74)$ com a variável PSRZ. Deste modo, pode se praticar a seleção de mudas para o sistema radicular sem a necessidade de destruição das mudas, com base no aumento do CRA.

\section{CONCLUSÕES}

O grupo de variáveis da parte aérea não é independente do grupo de variáveis do sistema radicular.

Por meio de seleção baseada em variáveis da parte aérea pode-se melhorar o sistema radicular, principalmente por meio do maior comprimento do ramo (CRA).

Pode-se praticar seleçáo de clones de guaraná para maior peso de raiz sem a necessidade de destruir as mudas, de modo indireto, realizando-se apenas mensuraçôes do comprimento dos ramos.

\section{BIBLIOGRAFIA CITADA}

Carvalho, C.G.P.; Oliveira, V.R.; Cruz, C.D.; Casali, V.W.D. 1999. Análise de trilha sob multicolinearidade em pimentão. Pesquisa Agropecuária Brasileira, 34(4): 603-613.

Coimbra, J.L.M.; Guidolin, A.F.; Carvalho, F.I.F. De; Azevedo, R. de. 2000. Correlações canônicas: II - Análise do rendimento de grãos de feijão e seus componentes. Ciência Rural, 30(1):31-35.

Correia, J.R. 1993. Uso de técnicas multivariadas no estudo das interrelaçóes de características do solo e da produtividade do eucalipto. Dissertaçáo de Mestrado, Universidade Federal de Viçosa, Viçosa, Minas Gerais, 106 pp.

Cruz, C.D. 2001. Programa Genes: versão Windows; aplicativo computacional em genética e estatística. UFV, Viçosa, Minas Gerais, 648 pp.

Cruz, C.D.; Regazzi, A.J. 2004. Modelos biométricos aplicados ao melhoramento genético. UFV, Imprensa Universitária, Viçosa, Minas Gerais, 480 pp.

Embrapa. 1998. Centro de Pesquisa Agroflorestal da Amazônia Ocidental. Boletim Agrometeorológico. Manaus: Embrapa CPAA, 23 pp.

Escobar, J.R. 1986. Relatório de atividade de pesquisa, convênio IICAEmbrapa/Uepae de Manaus 1981-86. Manaus: IICA-Embrapa, $117 \mathrm{pp}$.

Fernandes, F.L.; Mantovani, E.C.; Neto, H.B.; Nunes, V. de V. 2009. Efeitos de variáveis ambientais, irrigação e vespas predadoras sobre Leucoptera coffeella (Guérin-Méneville) (Lepidoptera: Lyonetiidae) no cafeeiro. Neotropical Entomology, 38(3): 410417.

Hotelling, H. 1933. Analysis of a complex os statistical variables into principal components. Journal of Educational Psychology, 24: 417-441

Hotelling, H. 1936. Simplified calculation of principal components. Psychometrika, 1: 27-35.

Kurek, A.J.; Carvalho, F.I.F.; Assmann, I.C.; Marchioro, V.; Cruz, P.J. 2001. Análise de trilha como critério de seleção indireta para rendimento de grãos em feijão. Revista Brasileira de Agrociência, 7(1): 29-32.

Nascimento Filho, F.J.; Ando, A.; Cruz, C.D.; Garcia, T.B. 1993. Análise de caminhamento em mudas de guaraná. Pesquisa Agropecuária Brasileira, 28(4): 447-452.

Ramalho, M.A.P.; Santos, J.B. dos; Zimmermann, M.J.O. 1993. Genética quantitativa em plantas autógamas: aplicaçôes ao melhoramento do feijoeiro. Editora UFG, Goiânia, GO, Brasil. $271 \mathrm{pp}$.

Rigão, M.H.; Storck, L.; Bisognin, D.A.; Lopes, S.J. 2009. Correlação canônica entre caracteres de tubérculos para seleção precoce de clones de batata. Ciência Rural, online. 7 pp.

Recebido em 31/01/2011

Aceito em 01/05/2011 